\author{
SANDIA REPORT \\ SAND2010-6880 \\ Unlimited Release \\ August 2010
}

\title{
Preliminary characterization of active MEMS valves
}

\author{
Casey Anderson Barnard
}

Prepared by

Sandia National Laboratories

Albuquerque, New Mexico 87185 and Livermore, California 94550

Sandia National Laboratories is a multi-program laboratory managed and operated by Sandia Corporation, a wholly owned subsidiary of Lockheed Martin Corporation, for the U.S. Department of Energy's

National Nuclear Security Administration under contract DE-AC04-94AL85000.

Approved for public release; further dissemination unlimited. 
Issued by Sandia National Laboratories, operated for the United States Department of Energy by Sandia Corporation.

NOTICE: This report was prepared as an account of work sponsored by an agency of the United States Government. Neither the United States Government, nor any agency thereof, nor any of their employees, nor any of their contractors, subcontractors, or their employees, make any warranty, express or implied, or assume any legal liability or responsibility for the accuracy, completeness, or usefulness of any information, apparatus, product, or process disclosed, or represent that its use would not infringe privately owned rights. Reference herein to any specific commercial product, process, or service by trade name, trademark, manufacturer, or otherwise, does not necessarily constitute or imply its endorsement, recommendation, or favoring by the United States Government, any agency thereof, or any of their contractors or subcontractors. The views and opinions expressed herein do not necessarily state or reflect those of the United States Government, any agency thereof, or any of their contractors.

Printed in the United States of America. This report has been reproduced directly from the best available copy.

Available to DOE and DOE contractors from

U.S. Department of Energy

Office of Scientific and Technical Information

P.O. Box 62

Oak Ridge, TN 37831

Telephone: $\quad$ (865) 576-8401

Facsimile: (865) 576-5728

E-Mail:_reports@adonis.osti.gov

Online ordering: http://www.osti.gov/bridge

Available to the public from

U.S. Department of Commerce

National Technical Information Service

5285 Port Royal Rd.

Springfield, VA 22161

Telephone: $\quad$ (800) 553-6847

Facsimile: (703) 605-6900

E-Mail: $\quad$ orders@ntis.fedworld.gov

Online order: $\quad$ http://www.ntis.gov/help/ordermethods.asp?loc=7-4-0\#online

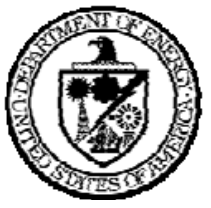


SAND2010-6880

Unlimited Release

August 2010

\title{
Preliminary characterization of active MEMS valves
}

\author{
Casey Anderson Barnard \\ 1749 \\ Sandia National Laboratories \\ P.O. Box 5800 \\ Albuquerque, New Mexico 87185-MS1080
}

\begin{abstract}
Partial characterization of a series of electrostatically actuated active microfluidic valves is to be performed. Tests are performed on a series of 24 valves from two different MEMS sets. Focus is on the physical deformation of the structures under variable pressure loadings, as well as voltage levels. Other issues that inhibit proper performance of the valves are observed, addressed and documented as well.
\end{abstract}




\section{ACKNOWLEDGMENTS}

I would first like to thank Paul Galambos, whom has been my primary advisor on this project. He has lent both wisdom and encouragement at the oft times when unexpected errors arose along the way. Also thanks go out to Thayne Edwards, as he helped in showing me a basic testing setup he used which proved very instrumental in implementing my own, as well as fastidiously turning out some new die for testing in the waning days of the summer. 


\section{CONTENTS}

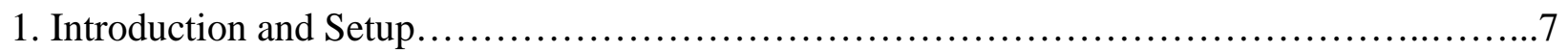

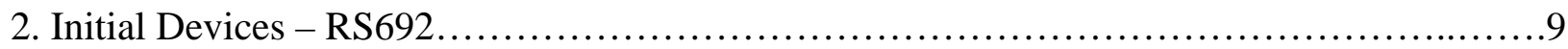

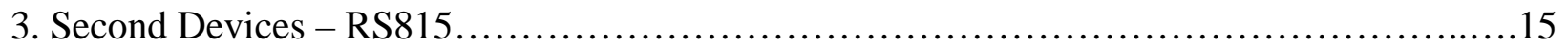

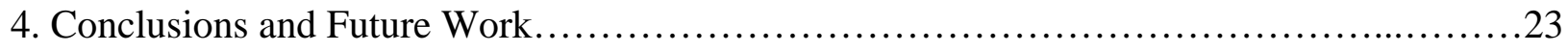

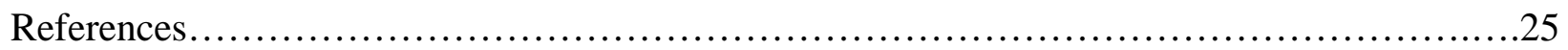

Appendix A: Extra Diagrams for RS692

Appendix B: Open Flow Rate Data for RS815

Appendix C: Pressure Deformation Data for RS815

Appendix D: Electrical Short Identification

\section{FIGURES}

Figure 1: Fabrication design of RS692 showing top, middle and bottom die..................9

Figure 2: Close up of ‘middle’ die, second valve.........................................10

Figure 3: D1, V2, with $150 \mathrm{~V}$ applied. Note the flatness of the $\mathrm{X}$ profile.......................11

Figure 4: Figure 4. D1 V2 with 10 Psig applied. Note mounding effect around center of boss...12

Figure 5: D2, Valve 3, showing stringer in the top right boss flow hole.......................13

Figure 6: Fabrication design of RS815 showing top, middle, and bottom die..................15

Figure 7: Close up of ‘middle’ die, first valve.........................................16

Figure 8: Figure 8. Chart detailing open flow rate of die A5 at various pressures...............17

Figure 9: Profile of A1, Valve 2, at zero voltage and 20 Psig..............................18

Figure 10: Profile of Valve 2, A1, showing deformation at $180 \mathrm{~V}$ and 0 Psig before short........9

Figure 11: Valve 1, A1, at $100 \mathrm{~V}$ and 50 Psig just before opening.............................20

Figure 12: Valve 1, A1, at $100 \mathrm{~V}$ and 50 Psig just after opening............................20 


\section{NOMENCLATURE}

$\begin{array}{ll}\text { V } & \text { Volts } \\ \text { Psig } & \text { Pounds per square inch gauge } \\ \text { sccm } & \text { Standard cubic centimeter per minute } \\ \text { um } & \text { Micron } \\ \text { mm } & \text { Millimeter } \\ \text { SEM } & \text { Scanning electron microscope } \\ \text { DOE } & \text { Department of Energy } \\ \text { SNL } & \text { Sandia National Laboratories }\end{array}$




\section{INTRODUCTION AND SETUP}

Many microfluidic applications have need for the distribution of gases at finely specified pressures and times. To this end a series of electrostatically actuated active valves have been fabricated. Eight separate silicon die are discussed, each with a series of four active valves present.

The devices are designed such that the valve boss is held at a ground, with a voltage applied to lower contacts. Resulting electrostatic forces pull the boss down against a series of stops, intended to create a seal as well as prevent accidental shorting of the device.

They have been uniquely packaged atop a stack of material layers, which have inlaid channels for application of fluid flow to the backside of the valve. Electrical contact is supplied from the underlying printed circuit board, attached to external supplies and along traces on the silicon.

Pressure is supplied from a reservoir of house compressed air, up to 100 Psig. This is routed through a Norgren R07-200-RGKA pressure regulator, rated to 150 Psig. From there flow passes a manually operated ball valve, and to a flow meter. Two flow meters were utilized; initially an Omega FMA1802 rated at $10 \mathrm{sccm}$, and followed by a Flocat model for higher flow rates up to 100 sccm. An Omega DPG4000-500 pressure gauge produced pressure measurements.

Optical measurements were returned via a WYKO Interferometry probe station. This would allow for determination of physical deformations of the device under a variety of voltage and pressure loads. This knowledge could lead to insight as to the failure mechanisms of the device, yielding improvements for subsequent fabrications. 


\section{INITIAL DEVICES - RS692}

The initial set of devices is from a series of silicon dies designated as RS692. The first, hereafter referred to as D1, is of the 'top' formation as seen in the corresponding AutoCAD diagram. D2, and D3 respectively, are both of the 'middle' formation. Each die has four valves, designated as V1, V2, V3, and V4, and are labeled as such.

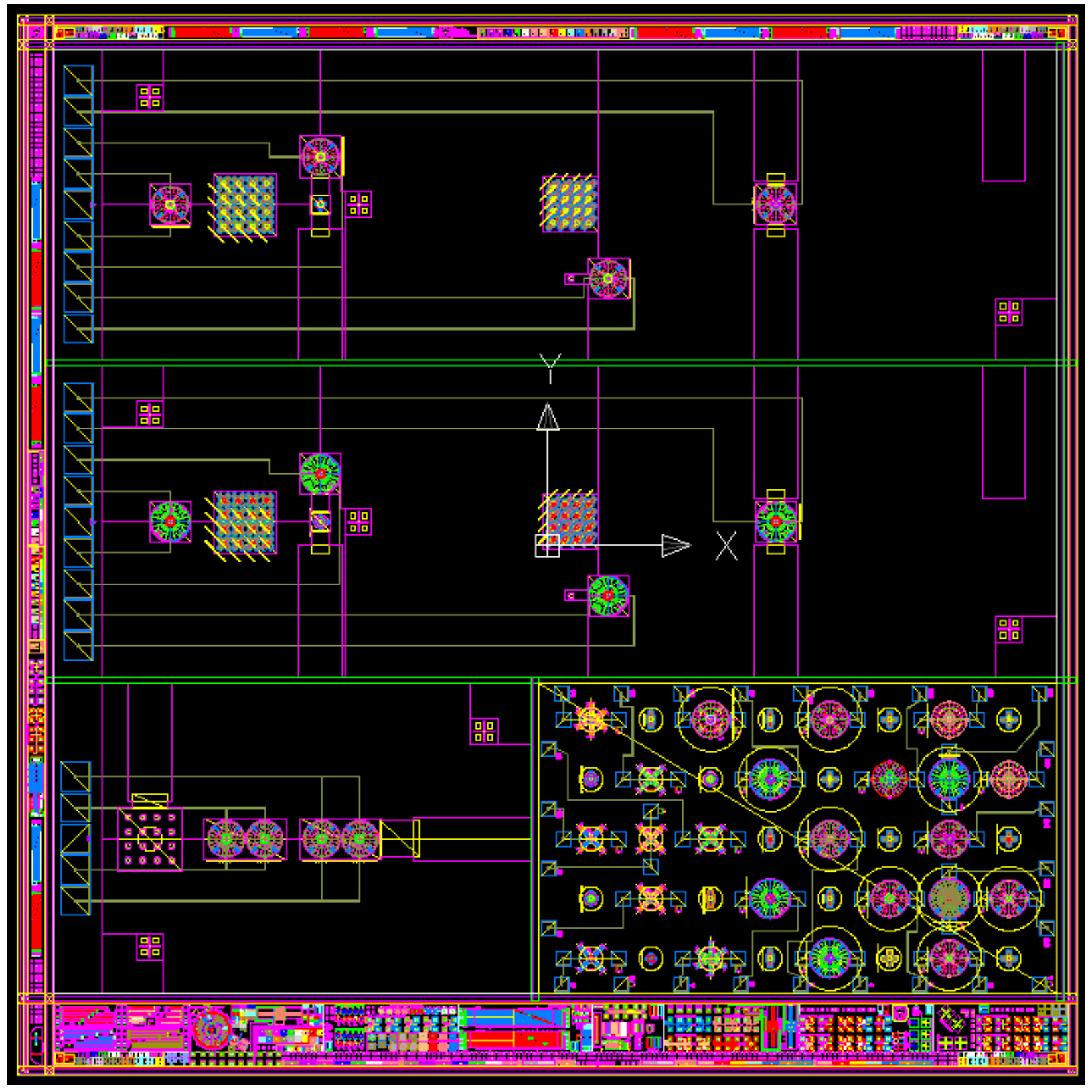

Figure 1. Fabrication design of RS692 showing top, middle and bottom die. 
The RS692 set of valves are typified by there inward directed springs around the outside of the boss. Additionally there is a recess in the center of the boss to increase structural rigidity and assist gas flow. When not being actuated the boss lies flat across its surface, with the edge ring of the valve being raised slightly. (See Appendix A for diagrams)

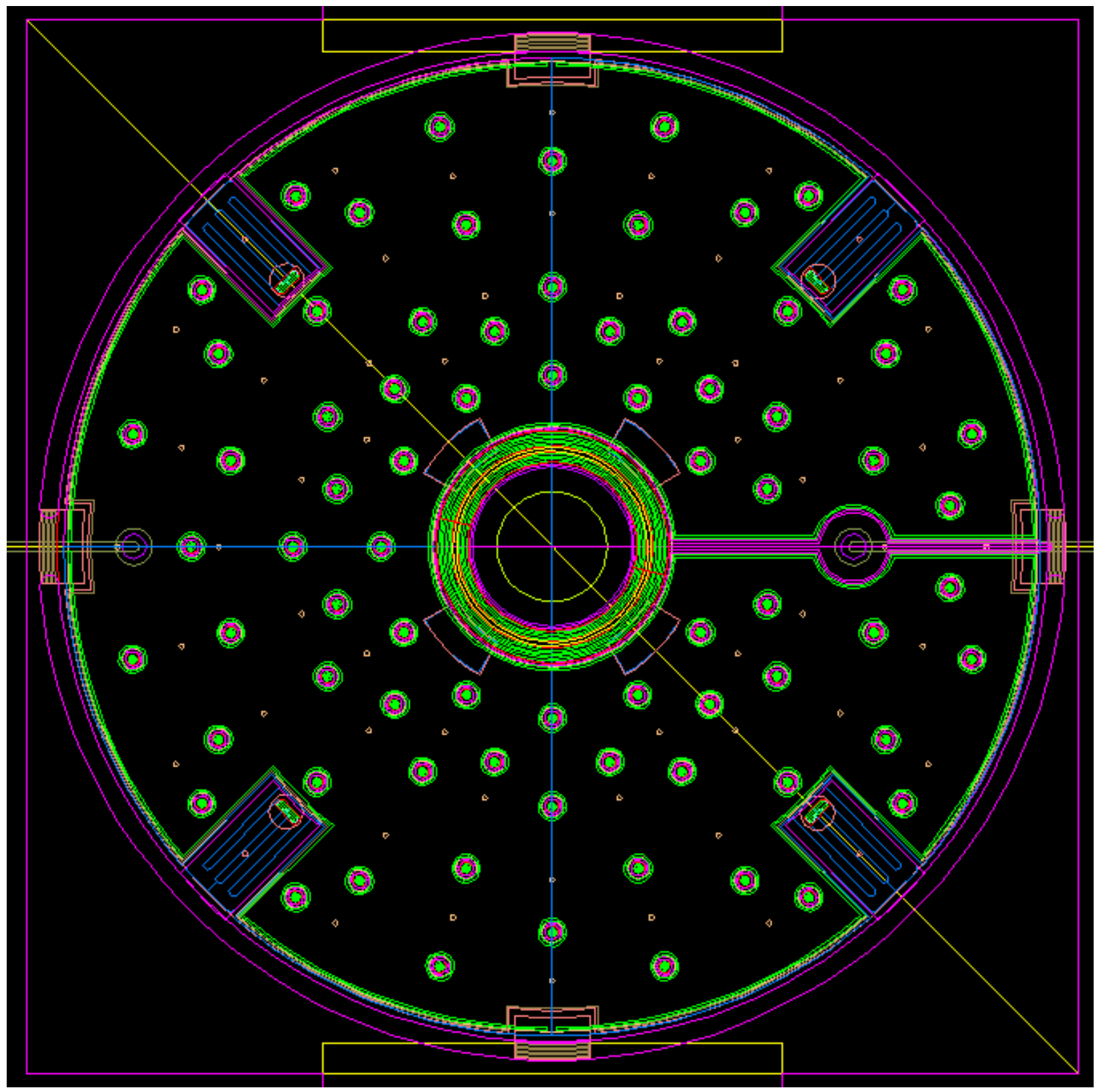

Figure 2. Close up of 'middle' die, second valve. 
When voltage was applied to these valves little or no actuation was seen. The total travel of the boss was well within the submicron range. Furthermore, the boss remained flat across the top, showing no indications of deformation around the stops as would be expected in proper operation. This lack of movement is ubiquitous across all twelve valves.

\section{Profile}

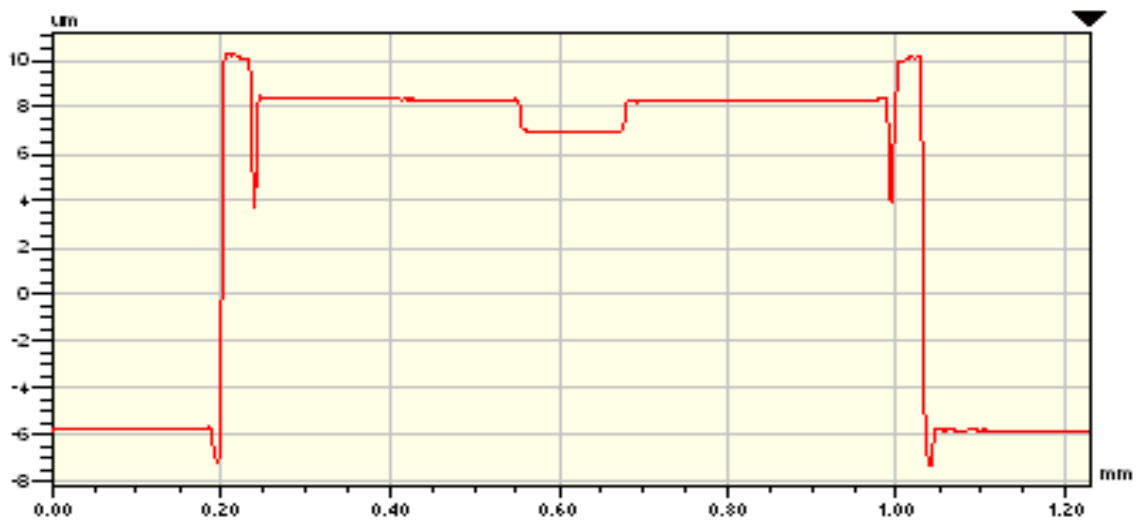

Y Profile

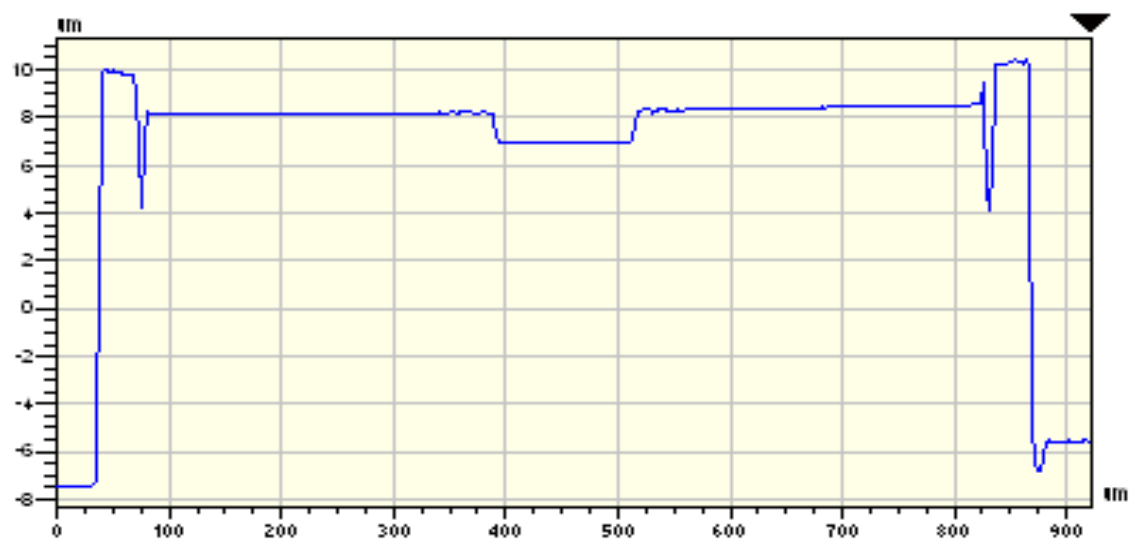

Figure 3. D1, V2, with $150 \mathrm{~V}$ applied. Note the flatness of the $\mathrm{X}$ profile.

However, one of the valves shows semi-repeatability. Valve 2 from D1 is able to hold a variety of pressures at different voltage levels. (See Appendix A for table) There are wide variations in these reported values though. This is indicative of a valve that is responding with greater closing force at a given voltage sometimes, and a lower force at others. 
This is confirmed by deformation due to pressure as expected. The center of the boss is greatly deformed with respect to the edges, creating a mounding effect. Once again this effect is seen in all twelve valves. Thus it appears all valves are mechanically functional as intended. Electrostatic actuation is not being performed as desired.

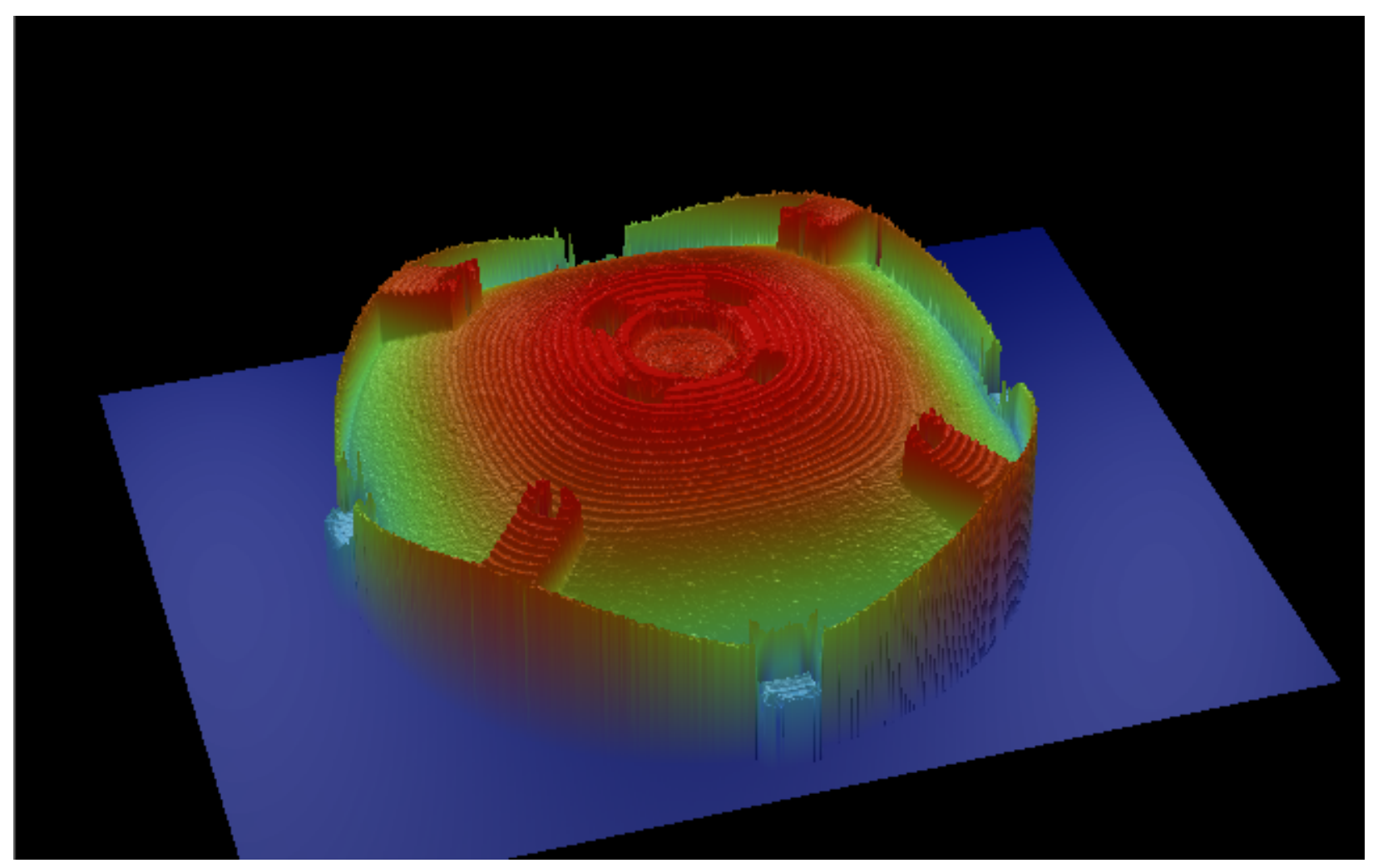

\section{Figure 4. D1 V2 with 10 Psig applied. Note mounding effect around center of boss.}

All twelve valves were thus tested for possible electrical shorts, and all twelve indicated that they were indeed shorting. Confirming this, a decreased voltage and resistance across the supply terminals was measured when connected to the device. However, this short was not always present. At times there was no voltage drop caused after being attached to the die, indicating an intermittent shorting pattern. The cause of this has not been fully determined, although possible evidence did arise. 
On multiple valves and different die stringers were identified on the SEM. It is possible that these stringers were allowing for direct contact across the intended gap, shorting the system. It is believed that these stringers are an artifact of the first sacrificial oxide layer used in fabrication. One stringer was measured as being at least 3 microns in thickness. (See Appendix A for more)

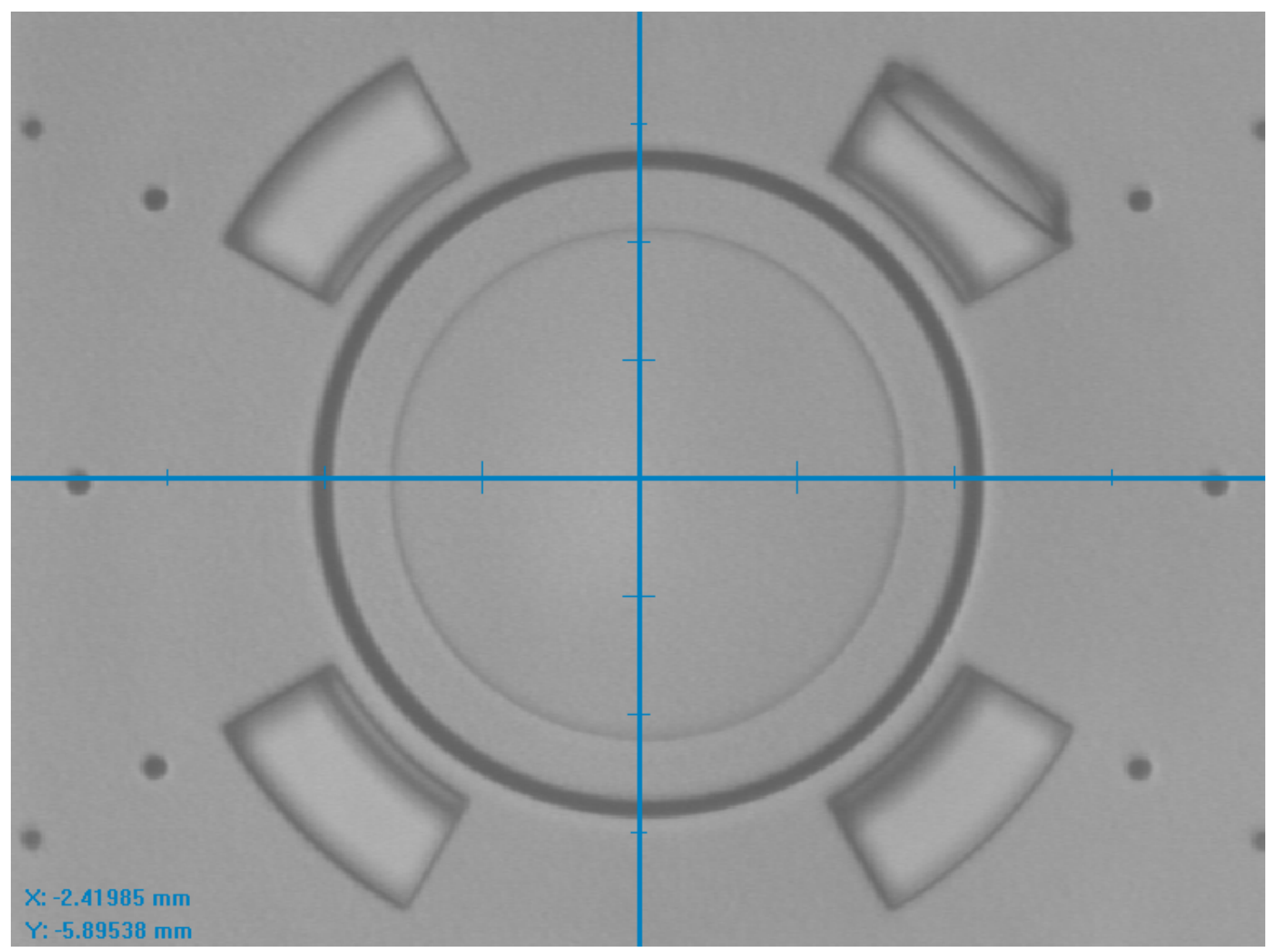

Figure 5. D2, Valve 3, showing stringer in the top right boss flow hole. 


\section{SECOND DEVICES - RS815}

The second set of valves fabricated are designated from RS815 AutoCAD scheme. A1 and A5 were of the 'top' formation, and A4 was from the 'middle.' As before there are four valves on each die labeled as V1, V2, V3, and V4.

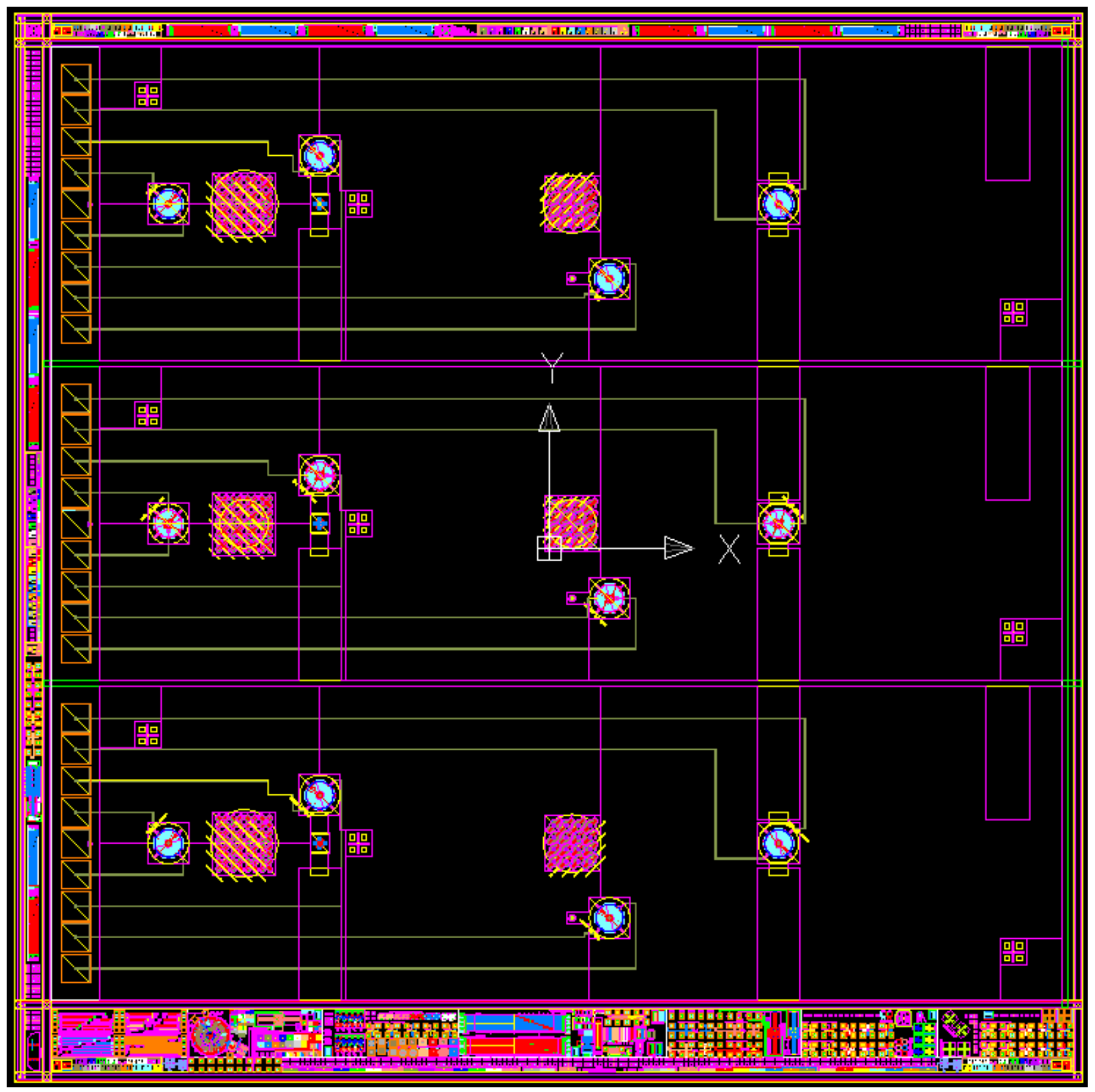

Figure 6. Fabrication design of RS815 showing top, middle, and bottom die. 
The RS815 set of valves are typified by there outward directed springs around the outside of the boss. In contrast to the RS692 valves, the boss lies flat across the top, aside from the holes for fluid flow. As before the boss is intended to have a planar surface before actuation. (See Appendix B for diagrams)

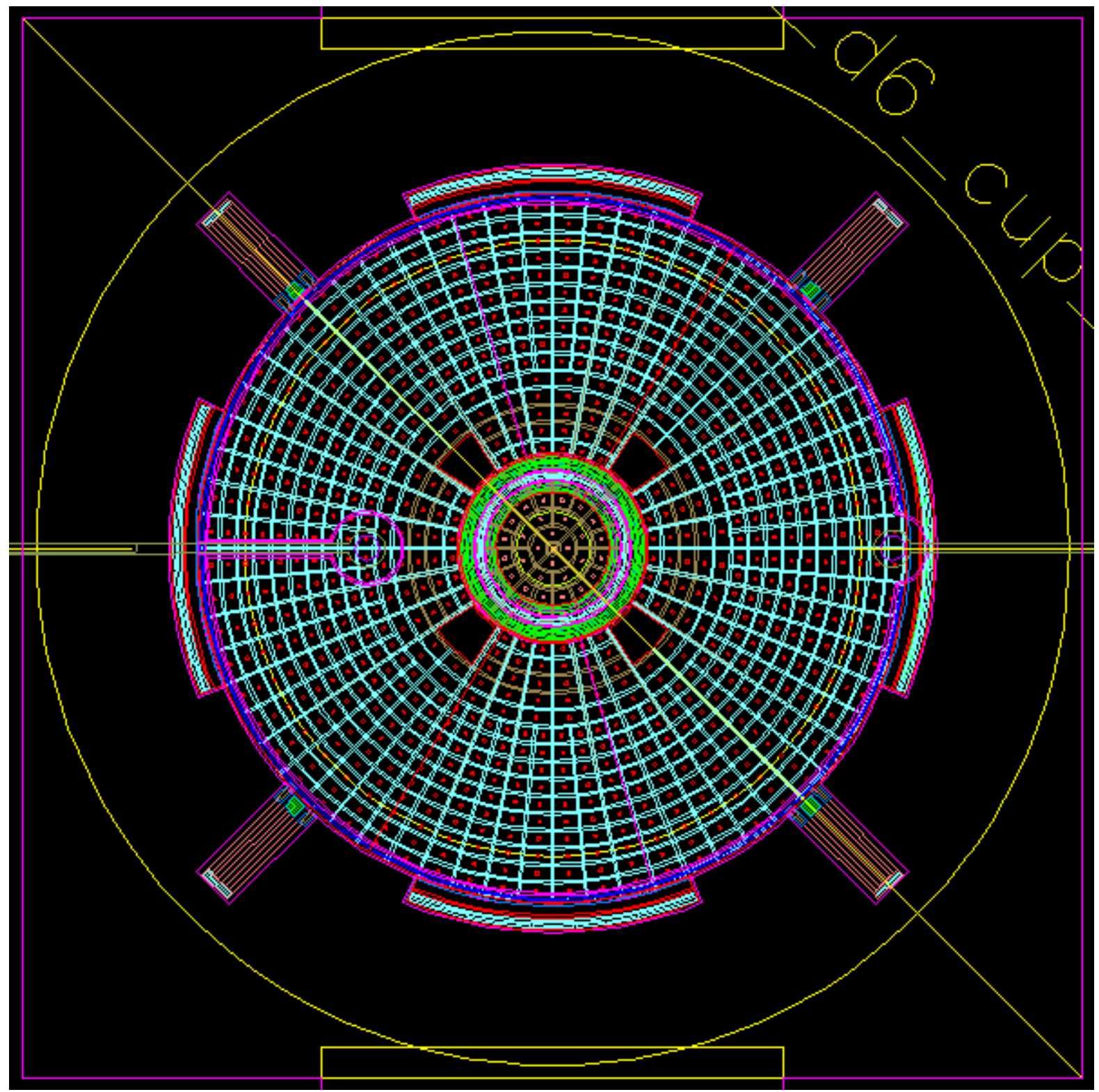

Figure 7. Close up of 'middle’ die, first valve. 
Initial characterization of these valves began with measurement of the open flow rates. With zero voltage applied, and a higher volume flow meter, pressure was incrementally increased from 0 to 20 Psig. The resulting flow trends were fairly constant, ranging to nearly $12 \mathrm{sccm}$ at 20 Psig. From 3 to 6 Psig there was little no increase in flow, hovering around the $4 \mathrm{sccm}$ mark. There were exceptions of a few outlier valves. Most notably Valve 2 of A5, which returned values at a near consistent factor of four higher. Valve 4 of A1 returned exceptionally low values, about a third of the norm. Valve 3, also of A1, showed an erratic flow pattern, the cause of which remains undetermined. (See Appendix B for tables and charts)

A5 - Open Flow Rates

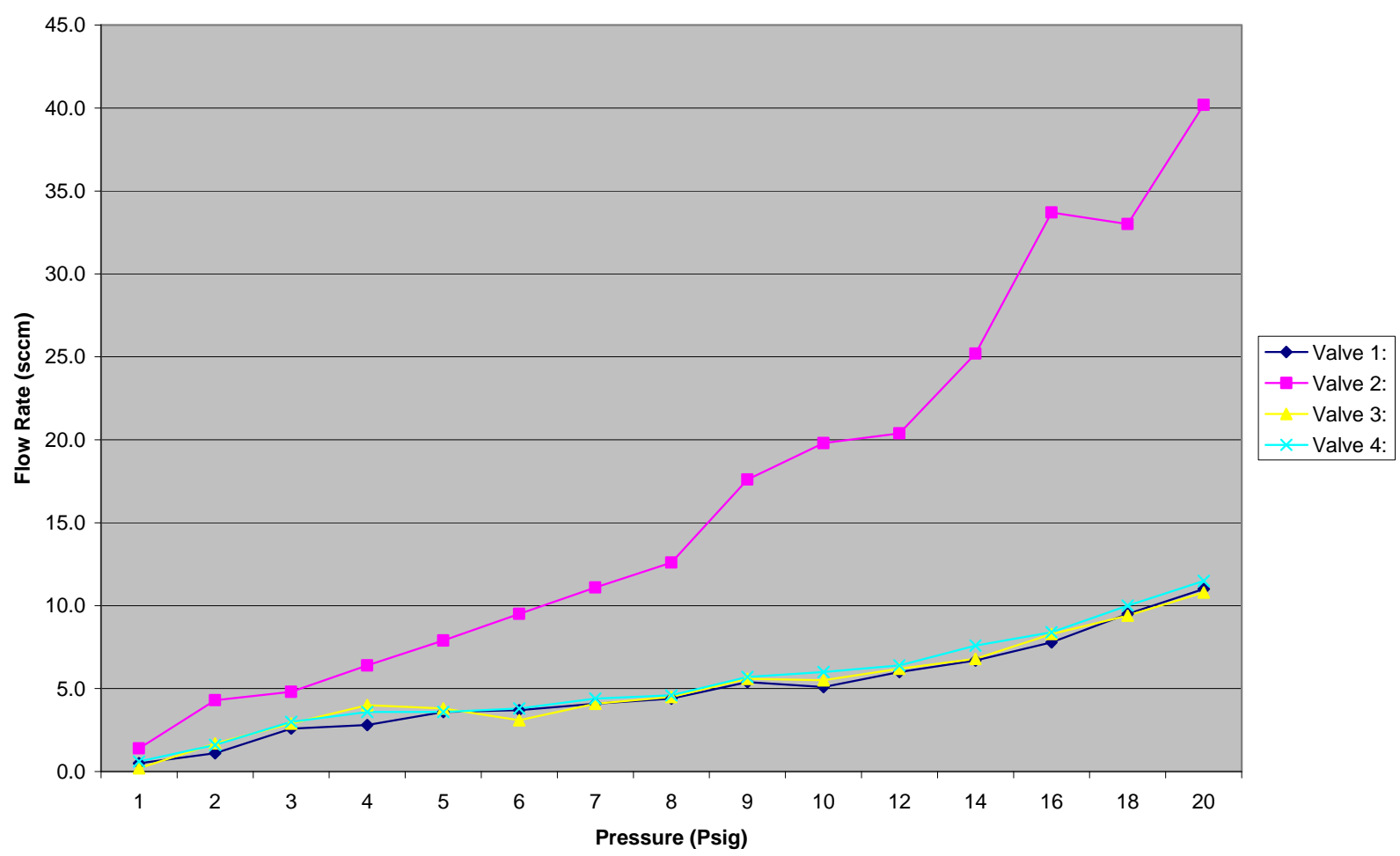

Figure 8. Chart detailing open flow rate of die A5 at various pressures.

Subsequently, interferometry measurements were taken from 0 to 20 Psig. Two separate scans were performed at each pressure increment. A long scan of 30 micron depth was used to calculate the height form the center line of the boss to the substrate below. Shorter scans of 5 microns in depth were used for higher resolution details of the diaphragm deflection. This allowed for calculation of the angle of deflection at the edge of the boss. 


\section{Profile}
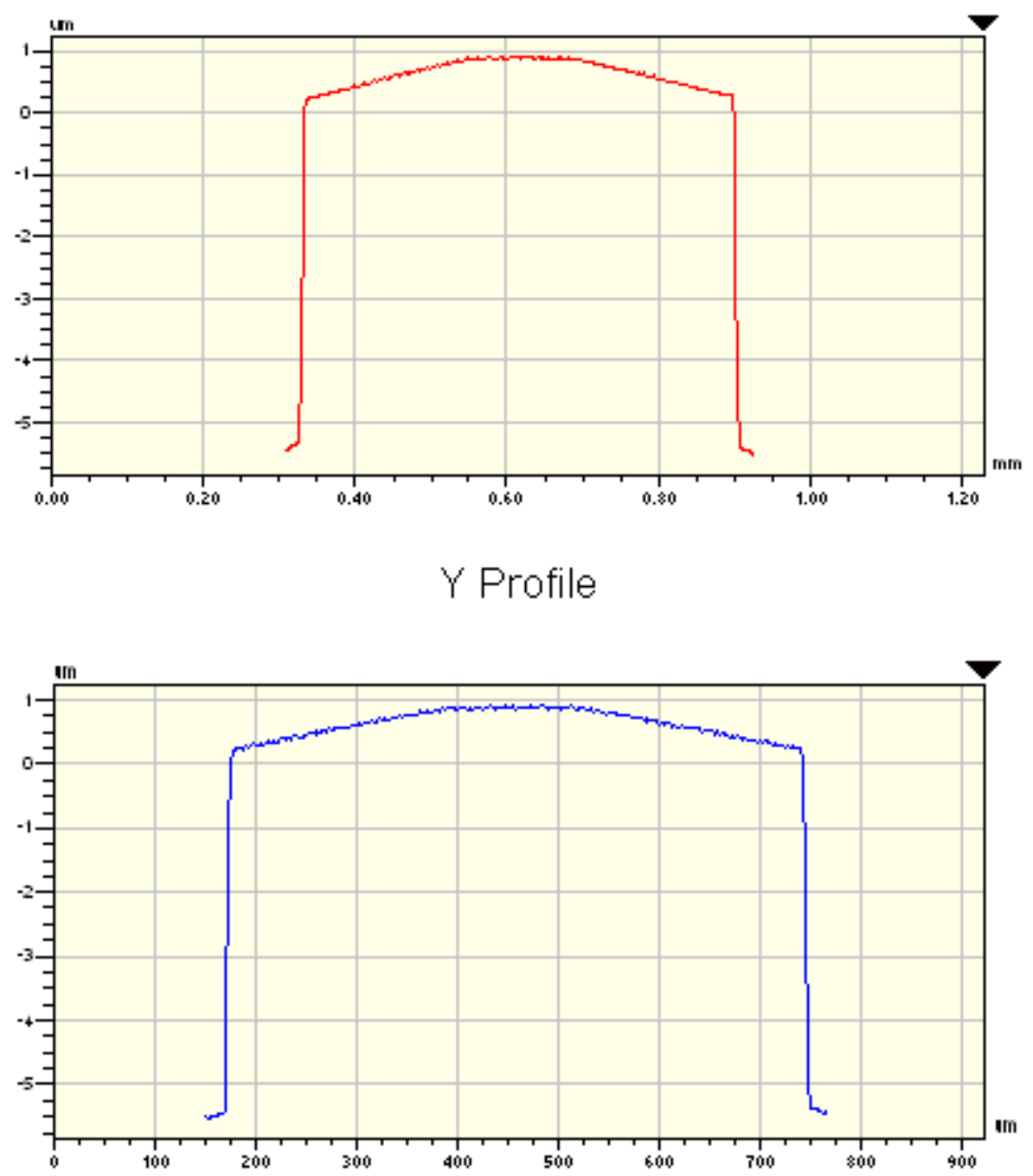

Figure 9. Profile of A1, Valve 2, at zero voltage and 20 Psig.

The average height of the boss was 14 microns above the substrate before pressure was applied. About half of the valves deformed linearly with increasing pressure, averaging a final height of 17 microns. All four valves on A4 showed this trend. Remaining valves generally exhibited little to no overall height change with increasing pressure. A5 exhibited three such valves. A1 showed two valves behaving in accordance with either theme. As expected the calculated edge angle is directly correlated to the overall height difference. All valves that did show significant deformation did so with increasing intensity in a manner similar to that seen in Figure 9. (See Appendix C for full tables) 
Valves were then tested for electrical shorts in the same way as before. Of these two valves had large shorts, four had small shorts (noted as shorts resulting in a smaller than $20 \%$ voltage drop), and the remaining six did not display shorts at that time. It should be noted that this does not guarantee they do not short, as all previously detected have been somewhat intermittent in nature. (See Appendix D for short identification)

Of the valves that did not display shorts, noticeable and repeatable deflections were identified with application of voltage alone. When high voltage was applied an annulus was formed, deflecting the boss in a trough around the center. The center and edges remained elevated above the underlying stops, as expected. However, increasingly high voltage levels pull the boss down excessively far, causing it to short with the substrate. This occurs around $180 \mathrm{~V}$ when no pressure is being applied.

\section{Profile}

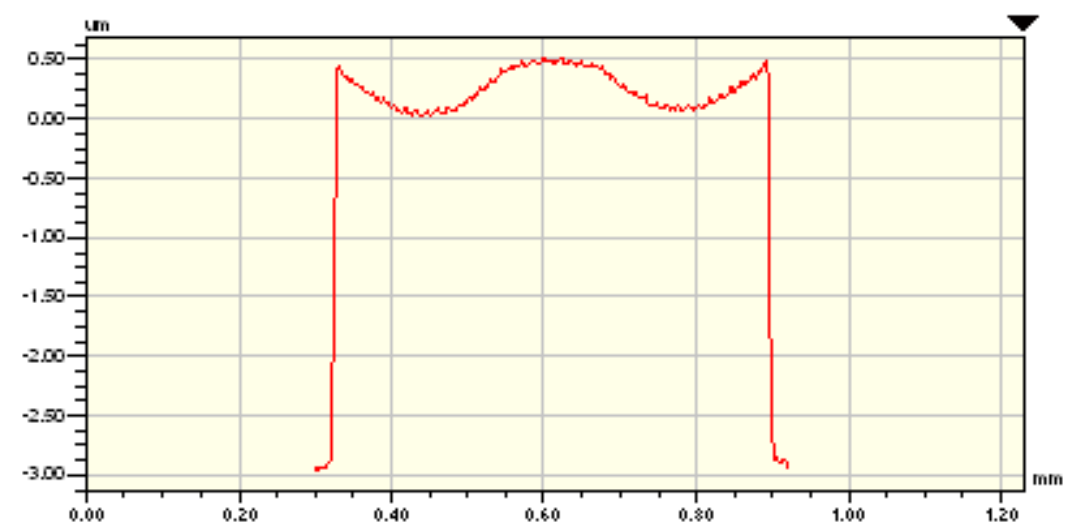

Y Profile

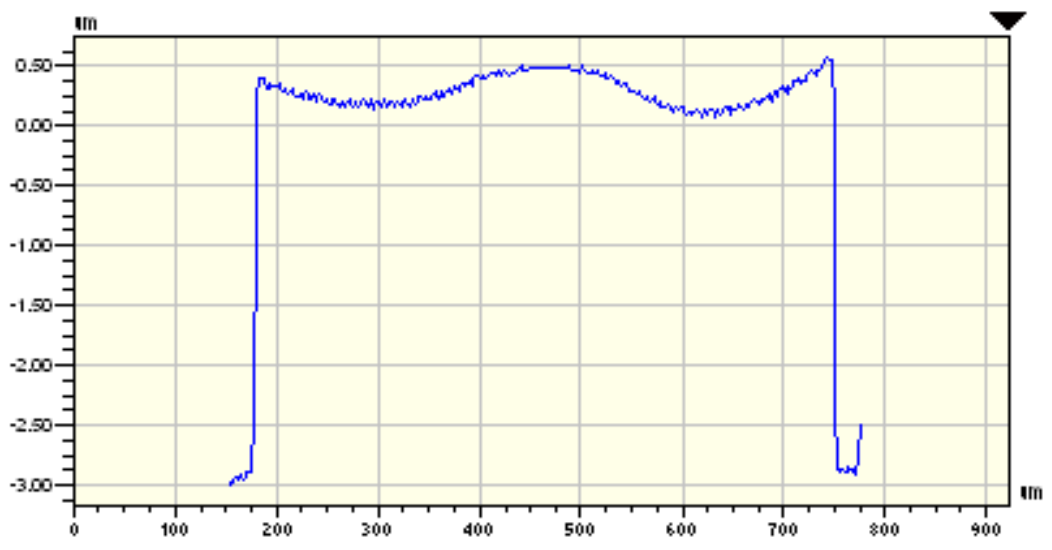

Figure 10. Profile of Valve 2, A1, showing deformation at $180 \mathrm{~V}$ and 0 Psig before short. 


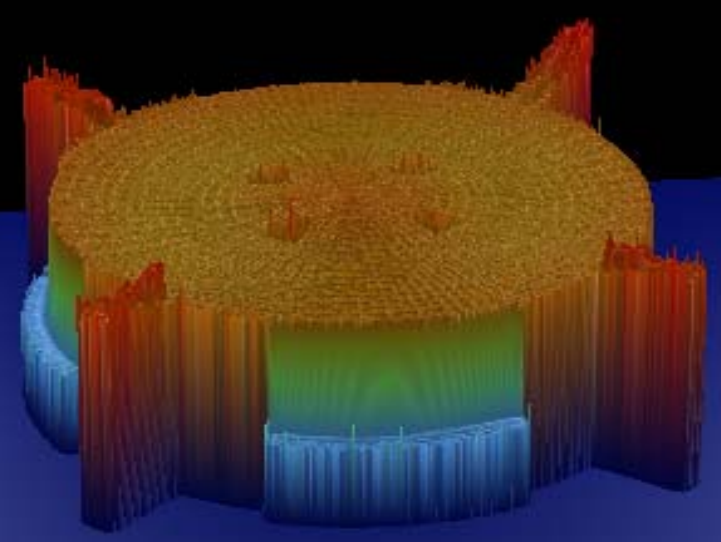

Figure 11. Valve 1, A1, at $100 \mathrm{~V}$ and 50 Psig just before opening.

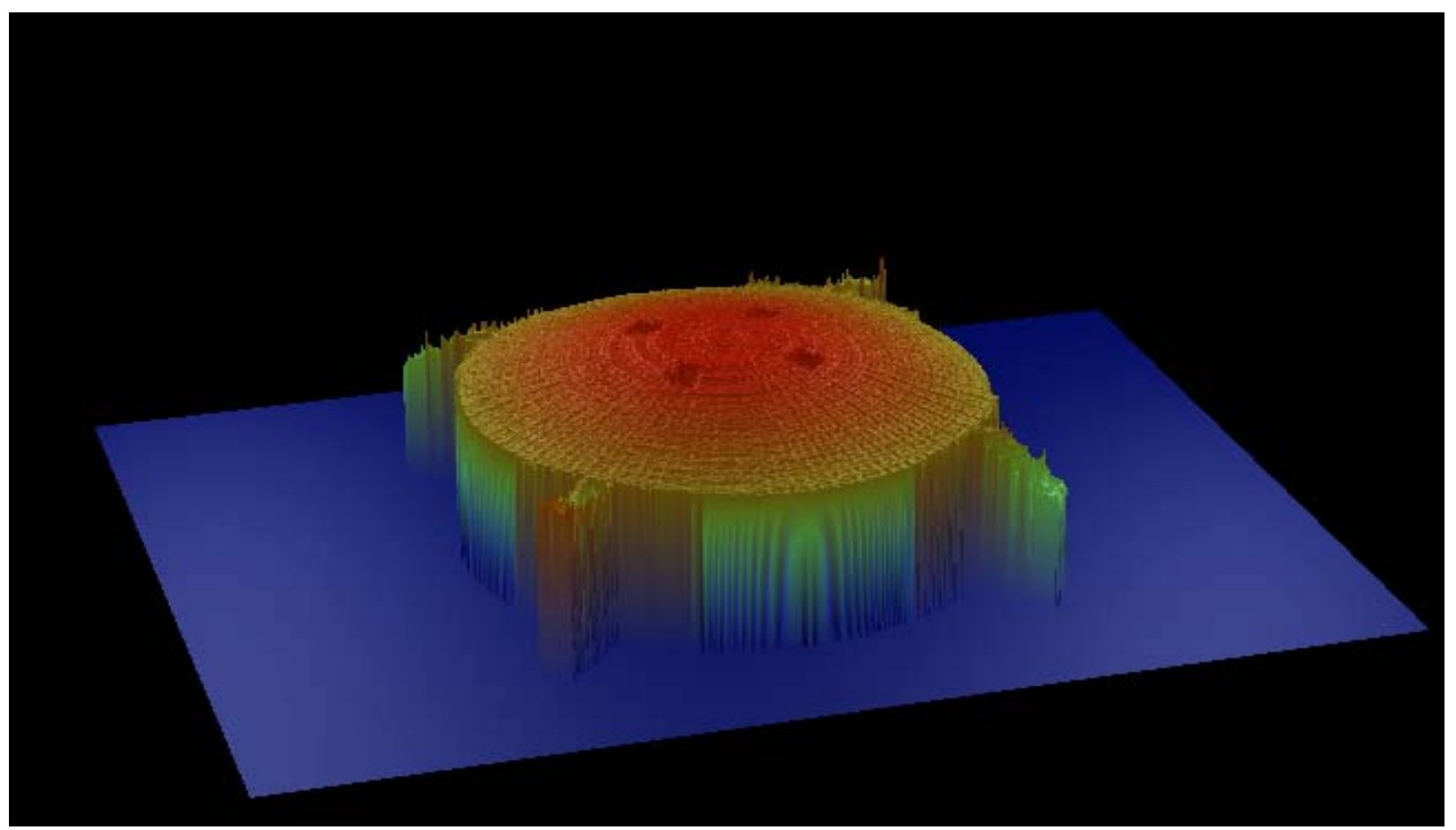

Figure 12. Valve 2, A1, at $100 \mathrm{~V}$ and 50 Psig just after opening. 
As evidenced in Figures 11 and 12, it is possible for the valves to be electrostatically held against a rising pressure. In this case $100 \mathrm{~V}$ is used to hold against 50 Psig, and fails at that same point a short time later. This is proof of valve functionality, although it is yet to be fully characterized. 


\section{CONCLUSIONS AND FUTURE WORK}

The current RS692 model of valve fabrication method needs to be modified. For whatever reason these valves all display significant shorting. Before modifications can be done it is imperative to identify the location and cause of these shorts. Furthermore the structure of the device appears inferior to other valves. Deformation due to similar pressures is much greater for the RS692, indicating it might fail well before other designs.

Several of the RS815 valves show more promise. Not only does the boss retain more of its original design at higher pressures, but shorting appears to be less of an issue. However, it is very possible that the shorts that were detected might be indicative of a larger problem that could arise in future fabrications; therefore the shorts should be determined here as well.

What should be done is full characterization of the working valves against pressure. By creating thorough voltage to pressure curves needed to hold the valves closed valuable insight can be gained as to their operation. It is suggested that an automated approach be taken here that can digitally control and measure the voltage, pressure, and flow rates to narrow down the range of values over which the valves operate. 


\section{REFERENCES}

1. Galambos, Paul; James, Conrad; Lantz, Jeff. Passive MEMS Valves with Pre-set Operating Pressures for Micro-Gas-Analyzer (U), Sandia National Laboratories, Albuquerque, NM.

2. Galambos, Paul; James, Conrad; Lantz, Jeff. Low Leak Rate MEMS Valves for MicroGas-Analyzer Flow Control (U), Sandia National Laboratories, Albuquerque, NM. 


\section{APPENDIX A: EXTRA DIAGRAMS FOR RS692}

\section{XProfile}

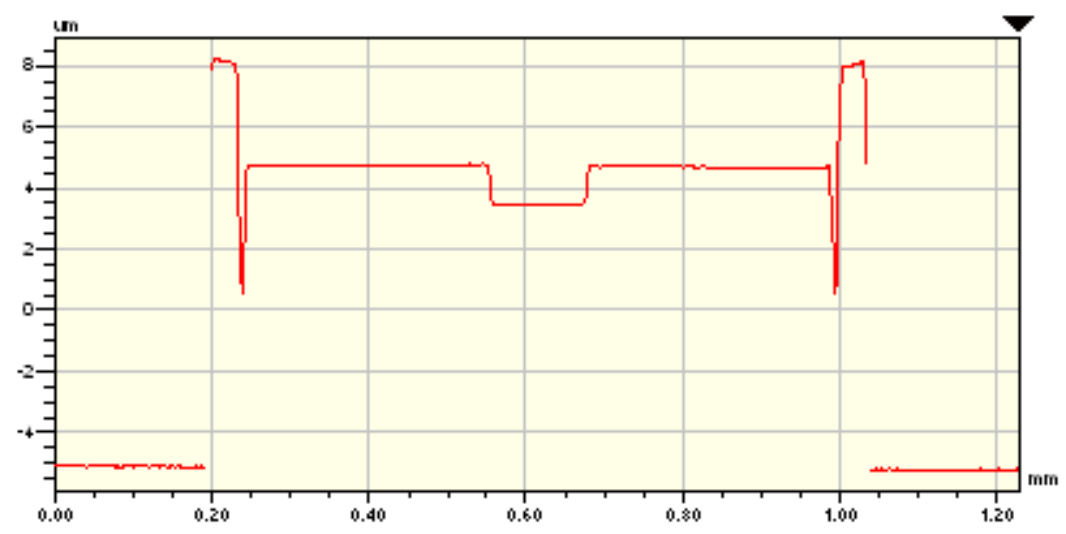

Y Profile

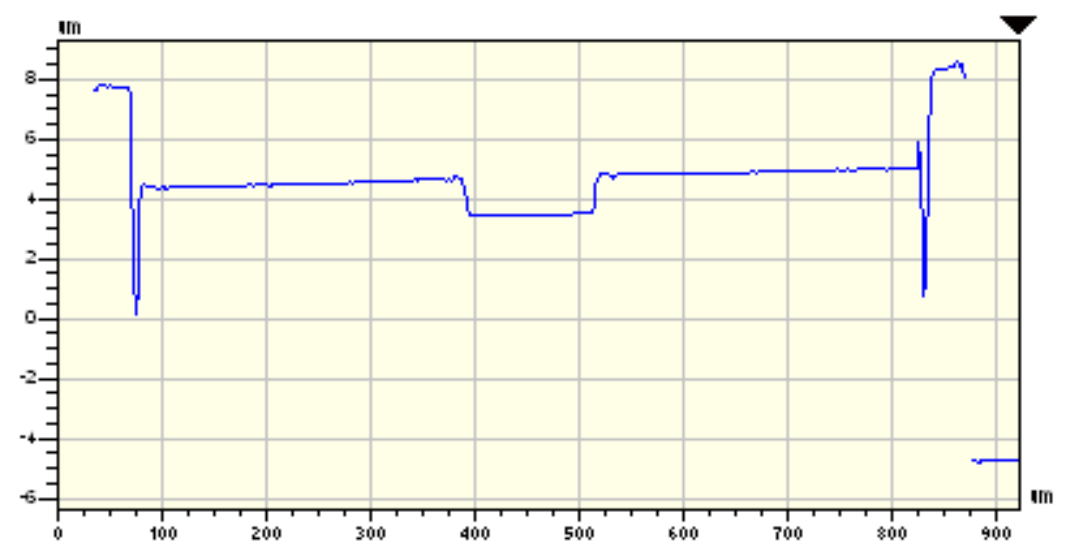

A1: Profile of Valve 2, D1, with no voltage or pressure applied. 


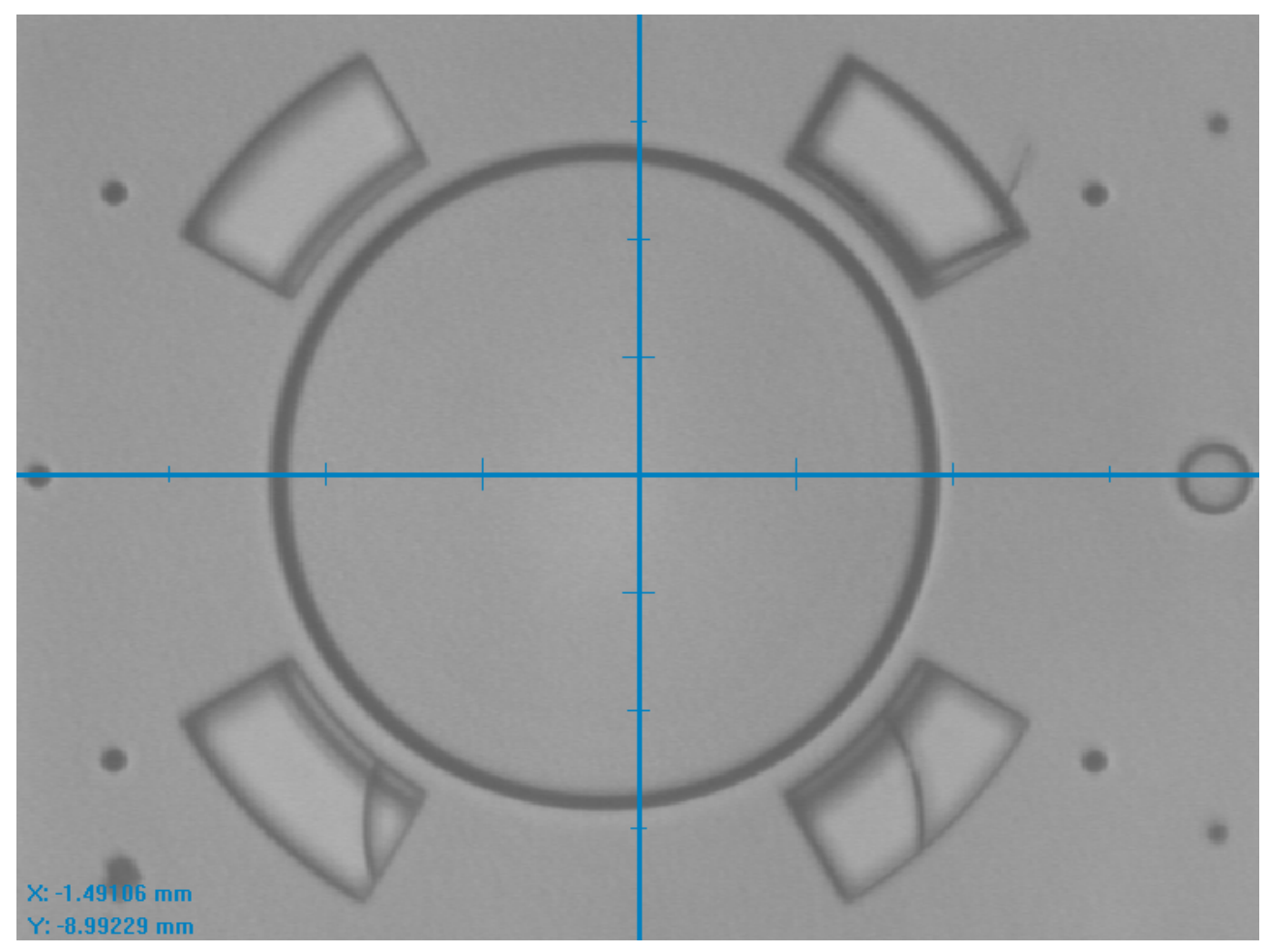

A2: SEM picture of Valve 3, D2, showing stringers in bottom flow holes.
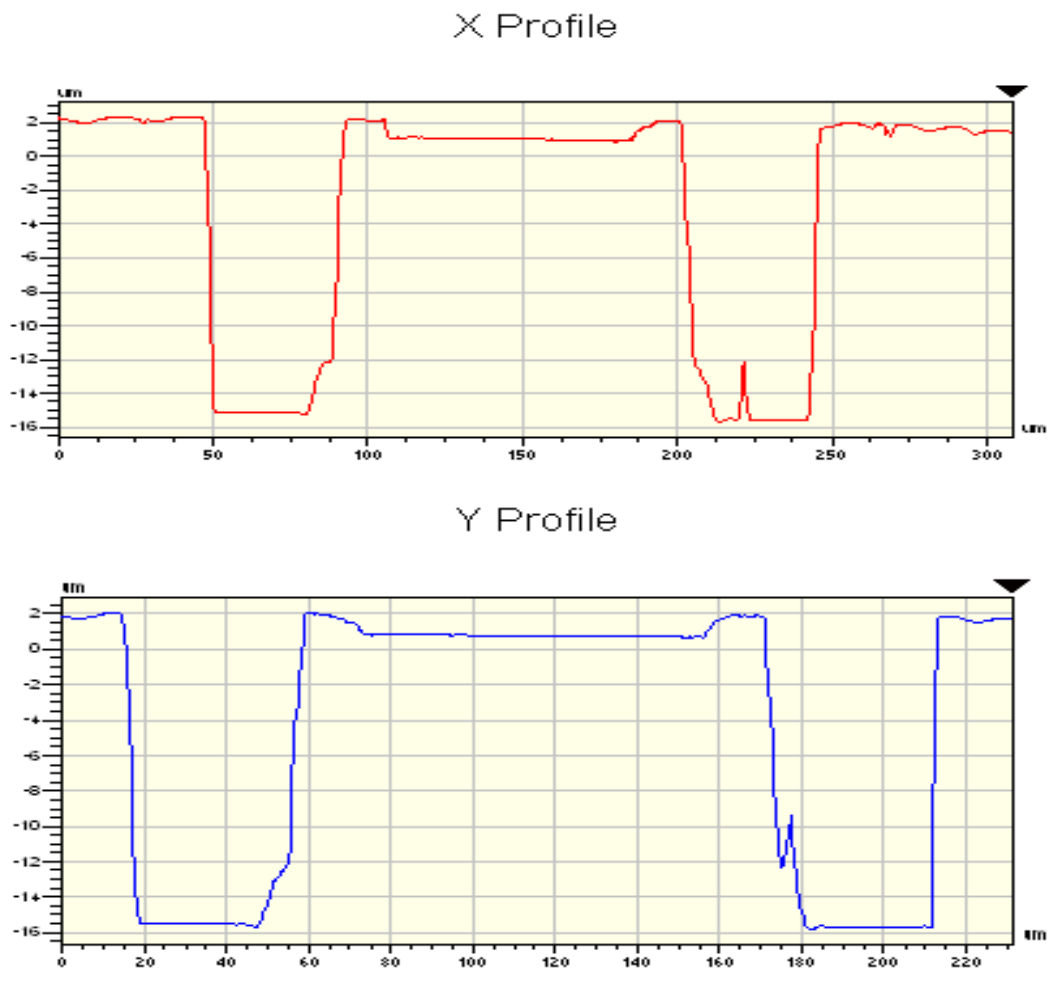

A3: Profile of Valve 3, D2 showing stringer disturbance on right side. 


\section{APPENDIX B: OPEN FLOW RATE DATA FOR RS815}

B1: Open flow rate data for A1

\section{A1 - Open Flow Rates (sccm):}

\begin{tabular}{|c|c|c|c|c|c|c|c|c|c|}
\hline \multirow{2}{*}{$\begin{array}{l}\text { Pressure: } \\
\text { Psig }\end{array}$} & \multirow[b]{2}{*}{ Leak: } & \multicolumn{2}{|c|}{ Valve 1: } & \multicolumn{2}{|c|}{ Valve 2: } & \multicolumn{2}{|c|}{ Valve 3: } & \multicolumn{2}{|c|}{ Valve 4: } \\
\hline & & Raw: & Adjusted: & Raw: & Adjusted: & Raw: & Adjusted: & Raw: & Adjusted: \\
\hline 1 & 1.0 & 1.4 & 0.4 & 1.6 & 0.6 & 1.3 & 0.3 & 1.4 & \\
\hline 2 & 1.4 & 2.6 & 1.2 & 3.2 & 1.8 & 3.2 & 1.8 & 2.8 & \\
\hline 3 & 2.0 & 5.4 & 3.4 & 4.5 & 2.5 & 6.5 & 4.5 & 3.1 & \\
\hline 4 & 3.1 & 6.4 & 3.3 & 6.0 & 2.9 & 5.2 & 2.1 & 5.6 & \\
\hline 5 & 4.2 & 7.6 & 3.4 & 8.4 & 4.2 & 6.2 & 2.0 & 6.4 & \\
\hline 6 & 5.8 & 9.2 & 3.4 & 10.1 & 4.3 & 7.3 & 1.5 & 7.4 & \\
\hline 7 & 7.1 & 11.3 & 4.2 & 13.9 & 6.8 & 8.6 & 1.5 & 9.1 & \\
\hline 8 & 8.4 & 12.9 & 4.5 & 14.1 & 5.7 & 13.1 & 4.7 & 10.5 & \\
\hline 9 & 9.2 & 14.4 & 5.2 & 15.8 & 6.6 & 11.5 & 2.3 & 11.6 & \\
\hline 10 & 10.8 & 16.1 & 5.3 & 18.5 & 7.7 & 17.0 & 6.2 & 13.3 & \\
\hline 12 & 13.8 & 19.5 & 5.7 & 21.0 & 7.2 & 15.1 & 1.3 & 15.7 & \\
\hline 14 & 16.4 & 23.4 & 7.0 & 24.3 & 7.9 & 18.3 & 1.9 & 18.4 & \\
\hline 16 & 19.0 & 27.0 & 8.0 & 29.1 & 10.1 & 20.4 & 1.4 & 21.2 & \\
\hline 18 & 21.3 & 30.7 & 9.4 & 31.6 & 10.3 & 23.4 & 2.1 & 24.5 & \\
\hline 20 & 24.1 & 34.7 & 10.6 & 35.4 & 11.3 & 26.4 & 2.3 & 27.6 & \\
\hline
\end{tabular}

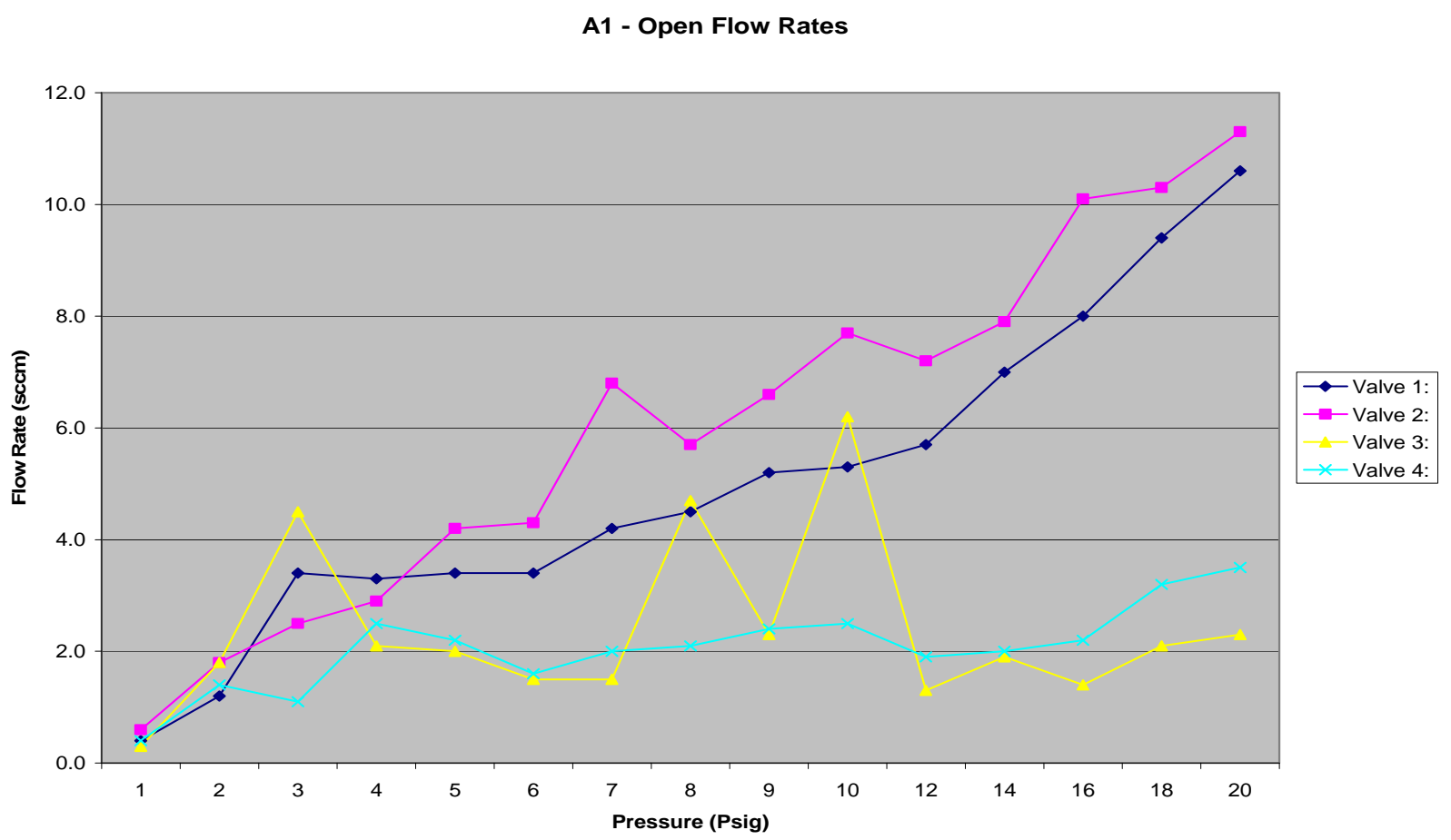

B2. Open flow rate chart for A1 
B3: Open flow rate data for A4

A4 - Open Flow Rates (sccm):

\begin{tabular}{|c|c|c|c|c|c|c|c|c|c|}
\hline \multicolumn{2}{|c|}{ Pressure: } & \multicolumn{2}{|c|}{ Valve 1: } & \multicolumn{2}{|c|}{ Valve 2: } & \multicolumn{2}{|c|}{ Valve 3: } & \multicolumn{2}{|c|}{ Valve 4: } \\
\hline Psig & Leak: & Raw: & Adjusted: & Raw: & Adjusted: & Raw: & Adjusted: & Raw: & Adjusted: \\
\hline 1 & 1.0 & 1.2 & 0.2 & 1.5 & 0.5 & 1.5 & 0.5 & 1.5 & 0.5 \\
\hline 2 & 1.4 & 3.1 & 1.7 & 3.3 & 1.9 & 3.1 & 1.7 & 3.2 & 1.8 \\
\hline 3 & 2.0 & 4.7 & 2.7 & 5.4 & 3.4 & 4.7 & 2.7 & 5.3 & 3.3 \\
\hline 4 & 3.1 & 6.4 & 3.3 & 6.6 & 3.5 & 6.3 & 3.2 & 6.5 & 3.4 \\
\hline 5 & 4.2 & 7.1 & 2.9 & 7.7 & 3.5 & 7.8 & 3.6 & 8.3 & 4.1 \\
\hline 6 & 5.8 & 9.2 & 3.4 & 9.9 & 4.1 & 9.5 & 3.7 & 9.4 & 3.6 \\
\hline 7 & 7.1 & 11.2 & 4.1 & 11.6 & 4.5 & 11.1 & 4.0 & 11.3 & 4.2 \\
\hline 8 & 8.4 & 13.0 & 4.6 & 13.6 & 5.2 & 13.2 & 4.8 & 13.4 & 5.0 \\
\hline 9 & 9.2 & 14.3 & 5.1 & 15.0 & 5.8 & 14.6 & 5.4 & 14.9 & 5.7 \\
\hline 10 & 10.8 & 16.4 & 5.6 & 17.2 & 6.4 & 16.5 & 5.7 & 16.5 & 5.7 \\
\hline 12 & 13.8 & 19.8 & 6.0 & 20.4 & 6.6 & 19.8 & 6.0 & 20.2 & 6.4 \\
\hline 14 & 16.4 & 23.8 & 7.4 & 24.7 & 8.3 & 24.0 & 7.6 & 24.2 & 7.8 \\
\hline 16 & 19.0 & 26.9 & 7.9 & 27.9 & 8.9 & 27.4 & 8.4 & 27.8 & 8.8 \\
\hline 18 & 21.3 & 30.5 & 9.2 & 31.1 & 9.8 & 31.1 & 9.8 & 31.0 & 9.7 \\
\hline 20 & 24.1 & 35.2 & 11.1 & 35.6 & 11.5 & 34.8 & 10.7 & 35.1 & 11.0 \\
\hline
\end{tabular}

A4 - Open Flow Rates

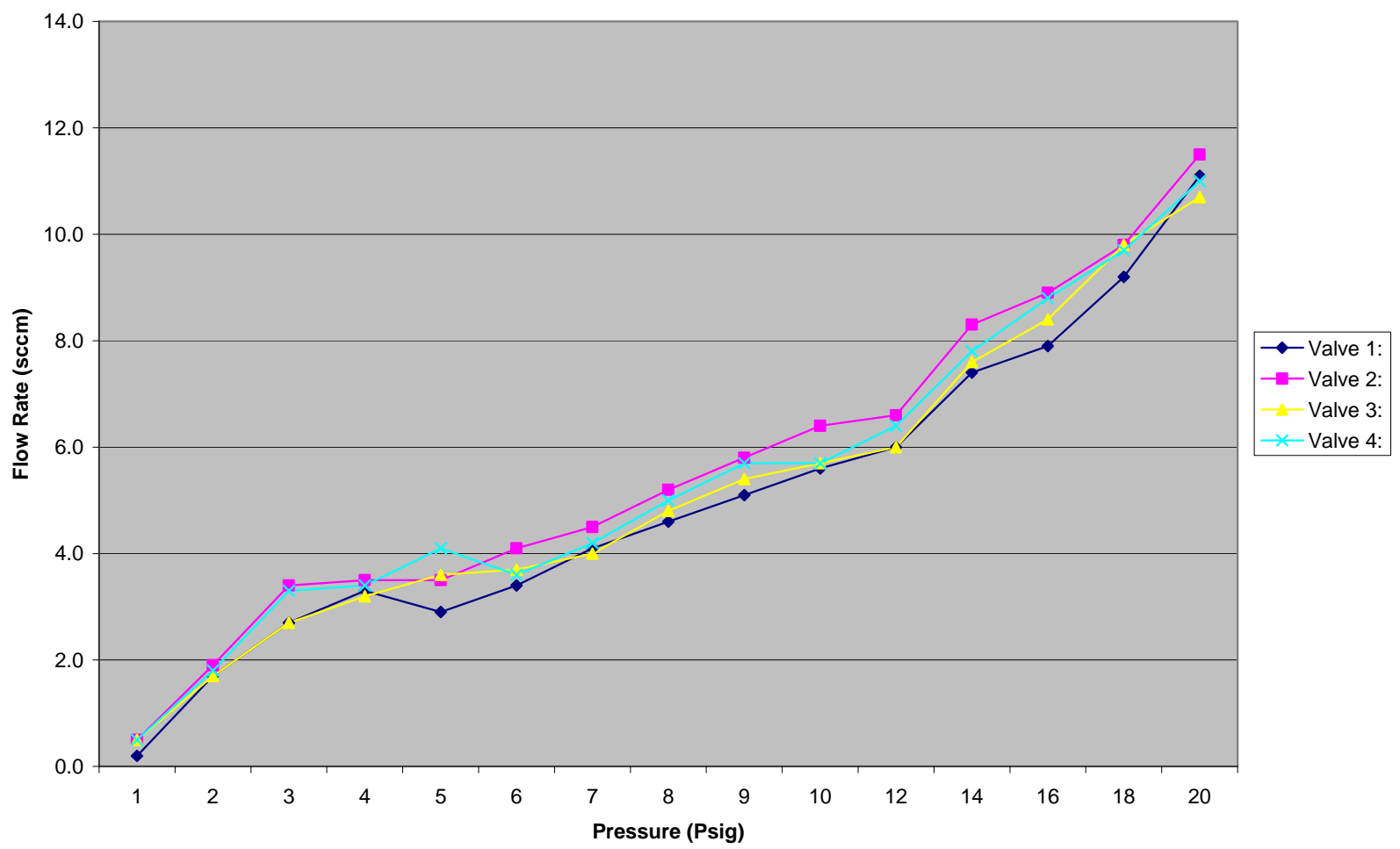

B4: Open flow rate chart for A4 
B5: Open flow rate data for A5

A5 - Open Flow Rates (sccm):

\begin{tabular}{|c|c|c|c|c|c|c|c|c|c|}
\hline \multicolumn{2}{|c|}{ Pressure: } & \multicolumn{2}{|c|}{ Valve 1: } & \multicolumn{2}{|c|}{ Valve 2: } & \multicolumn{2}{|c|}{ Valve 3: } & \multicolumn{2}{|c|}{ Valve 4: } \\
\hline Psig & Leak: & Raw: & Adjusted: & Raw: & Adjusted: & Raw: & Adjusted: & Raw: & Adjusted: \\
\hline 1 & 1.0 & 1.5 & 0.5 & 2.4 & 1.4 & 1.2 & 0.2 & 1.6 & 0.6 \\
\hline 2 & 1.4 & 2.5 & 1.1 & 5.7 & 4.3 & 3.1 & 1.7 & 3.0 & 1.6 \\
\hline 3 & 2.0 & 4.6 & 2.6 & 6.8 & 4.8 & 4.9 & 2.9 & 5.0 & 3.0 \\
\hline 4 & 3.1 & 5.9 & 2.8 & 9.5 & 6.4 & 7.1 & 4.0 & 6.7 & 3.6 \\
\hline 5 & 4.2 & 7.8 & 3.6 & 12.1 & 7.9 & 8.0 & 3.8 & 7.8 & 3.6 \\
\hline 6 & 5.8 & 9.5 & 3.7 & 15.3 & 9.5 & 8.9 & 3.1 & 9.6 & 3.8 \\
\hline 7 & 7.1 & 11.2 & 4.1 & 18.2 & 11.1 & 11.2 & 4.1 & 11.5 & 4.4 \\
\hline 8 & 8.4 & 12.8 & 4.4 & 21.0 & 12.6 & 12.9 & 4.5 & 13.0 & 4.6 \\
\hline 9 & 9.2 & 14.6 & 5.4 & 26.8 & 17.6 & 14.8 & 5.6 & 14.9 & 5.7 \\
\hline 10 & 10.8 & 15.9 & 5.1 & 30.6 & 19.8 & 16.3 & 5.5 & 16.8 & 6.0 \\
\hline 12 & 13.8 & 19.8 & 6.0 & 34.2 & 20.4 & 20.0 & 6.2 & 20.2 & 6.4 \\
\hline 14 & 16.4 & 23.1 & 6.7 & 41.6 & 25.2 & 23.2 & 6.8 & 24.0 & 7.6 \\
\hline 16 & 19.0 & 26.8 & 7.8 & 52.7 & 33.7 & 27.3 & 8.3 & 27.4 & 8.4 \\
\hline 18 & 21.3 & 30.8 & 9.5 & 54.3 & 33.0 & 30.7 & 9.4 & 31.3 & 10.0 \\
\hline 20 & 24.1 & 35.1 & 11.0 & 64.3 & 40.2 & 34.9 & 10.8 & 35.6 & 11.5 \\
\hline
\end{tabular}

A5 - Open Flow Rates

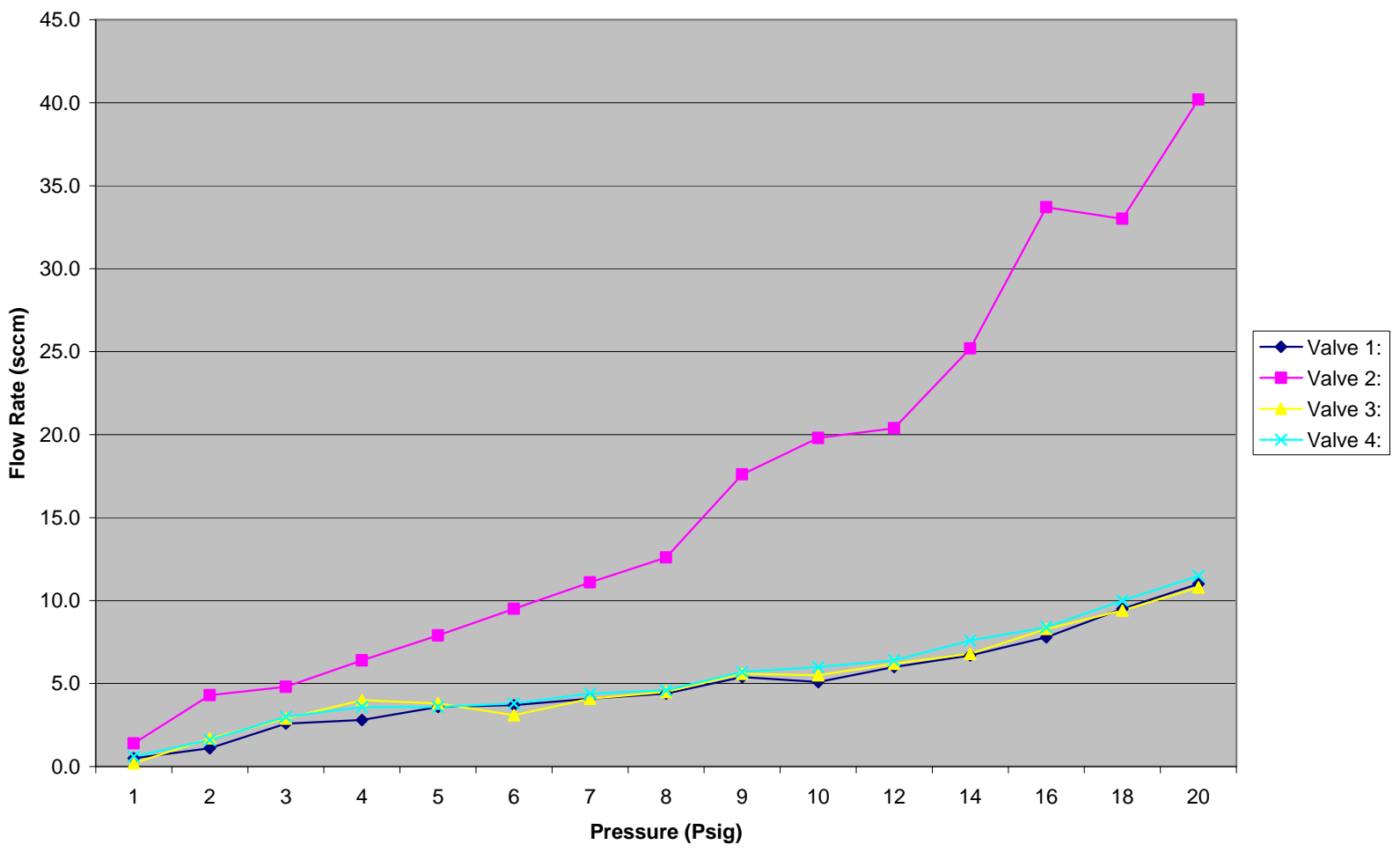

B6: Open flow rate chart for A5 


\section{APPENDIX C: PRESSURE DEFORMATION DATA FOR RS815}

\section{C1: Deformation data for A1}

\section{A1 - Characterization}

$\begin{array}{ll}\text { Pressure } & \\ \text { (Psig): } & \\ & 0 \\ & 2 \\ 4 \\ 6 \\ 8 \\ 10 \\ 12 \\ 14 \\ 16 \\ 18 \\ 20\end{array}$

Valve 3:

Pressure (Psig):

Open Height (um):

13.54

13.40

13.53

13.82

13.78

13.63

13.61

13.53

13.58

13.62

13.64

Valve 2:

\section{Open Edge}

Angle:

$-0.019$

0.012

0.011

0.057

0.062

0.082

0.102

0.120

0.147

0.161

0.173
Open Height (um):

14.19

16.36

16.57

16.53

16.63

16.64

16.74

16.90

16.96

17.03

17.13

Valve 4:

Open Edge

Angle:

$$
\begin{array}{r}
-0.011 \\
-0.013 \\
-0.015 \\
-0.005 \\
0.017 \\
0.009 \\
0.005 \\
0.001 \\
-0.001 \\
0.004 \\
0.003
\end{array}
$$

Open Edge Angle:
-0.011
0.001
0.039
0.037
0.059
0.077
0.094
0.111
0.131
0.162
0.159

Open Edge Angle:
-0.006
-0.007
-0.007
-0.010
-0.004
-0.008
-0.009
-0.011
-0.008
-0.009
-0.003


C2: Deformation data for A4

A4 - Characterization
Valve 1:

Pressure (Psig):

\begin{tabular}{rr}
\multicolumn{2}{c}{ Valve 1: } \\
\multicolumn{2}{l}{$\begin{array}{l}\text { Open Height } \\
\text { (um): }\end{array}$} \\
0 & 14.26 \\
2 & \\
4 & 15.07 \\
6 & 15.33 \\
8 & 15.42 \\
10 & 16.57 \\
12 & 16.58 \\
14 & 16.62 \\
16 & 16.71 \\
18 & 16.95 \\
20 & 17.02 \\
& 17.09
\end{tabular}

Valve 3:

Pressure (Psig):

Open Height (um):

\section{Open Edge} Angle:

$-0.019$

0.014

0.023

0.027

0.039

0.056

0.067

0.078

0.089

0.117

0.116

14.01

16.39

16.49

16.49

16.57

16.58

16.75

16.74

16.55

16.64

16.42

\section{Open Edge}

Angle:

$-0.18$

0.043

0.076

0.075

0.089

0.097

0.106

0.104

0.071

0.153

0.214
Valve 2:

Open Height (um):

14.06

14.92

15.10

15.13

15.32

15.38

15.48

15.53

15.74

15.76

15.85

Valve 4:

Open Height (um):

14.89

16.28

16.47

17.16

17.38

17.62

17.30

17.39

17.19

17.86

17.90
Open Edge Angle: 0.003

0.054

0.020

0.036

0.053

0.069

0.081

0.100

0.117

0.126

0.137

Open Edge Angle: $-0.021$

0.002

0.005

0.028

0.071

0.079

0.076

0.077

0.121

0.145

0.158 
C3: Deformation data for A5

\section{A5 - Characterization}

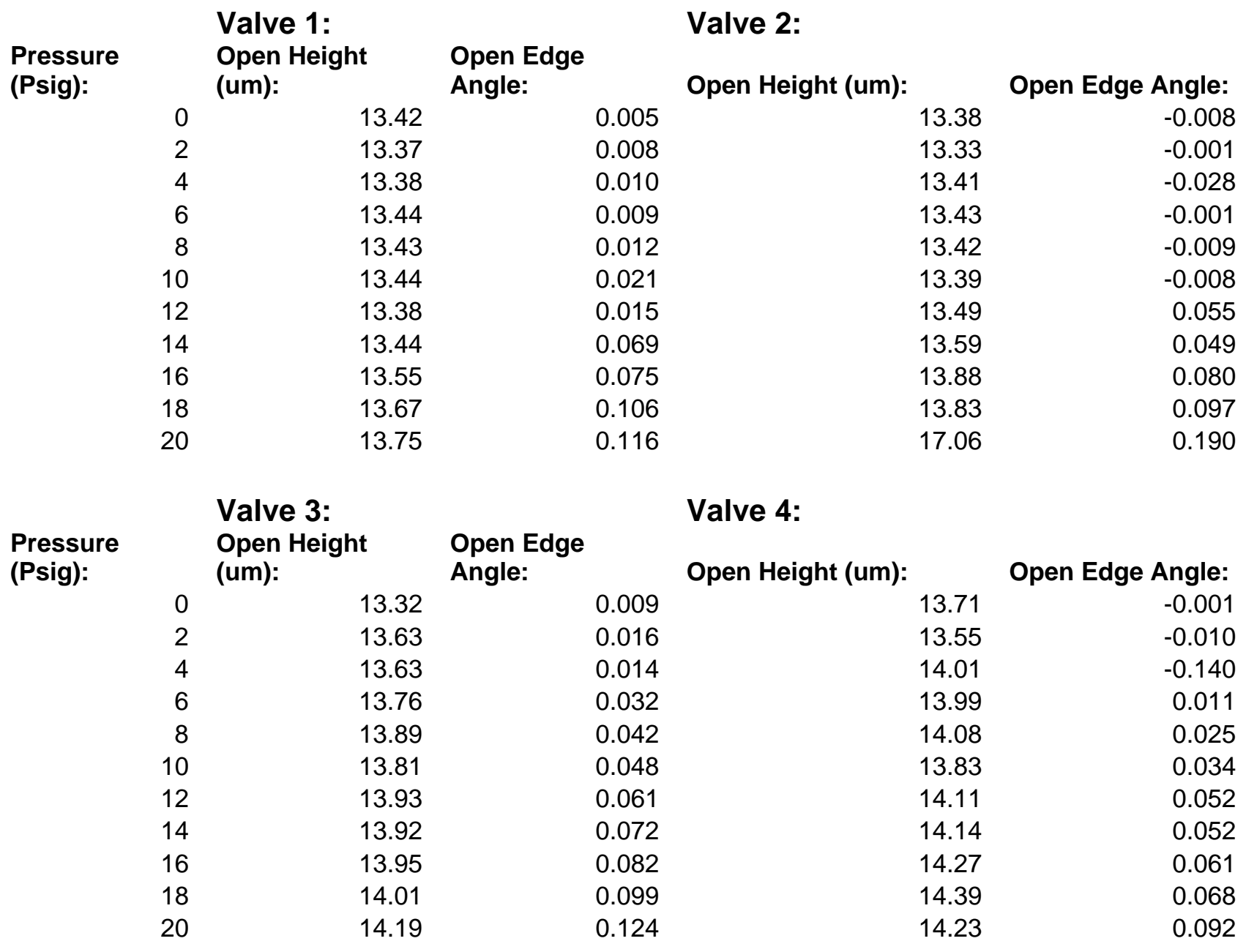




\section{APPENDIX D: ELECTRICAL SHORT IDENTIFICATION}

D1: Table of confirmed electrical shorts

\section{Valves Displaying Intermittent Shorts:}

$\begin{array}{lllllll}\text { Die: } & \text { A1: } & & \text { A4: } & & \text { A5: } \\ \text { Valve: } & \text { V1: } & \text { No } & \text { V1: } & \text { No } & \text { V1: } & \text { No } \\ & \text { V2: } & \text { No } & \text { V2: } & \text { Yes } & \text { V2: } & \text { No } \\ & \text { V3: } & \text { Small } & \text { V3: } & \text { No } & \text { V3: } & \text { Small } \\ & \text { V4: } & \text { Small } & \text { V4: } & \text { Yes } & \text { V4: } & \text { Small } \\ & & & & & & \\ \text { Die: } & \text { D1: } & & \text { D2: } & & \text { D3: } & \\ \text { Valve: } & \text { V1: } & \text { Yes } & \text { V1: } & \text { Yes } & \text { V1: } & \text { Yes } \\ & \text { V2: } & \text { Yes } & \text { V2: } & \text { Yes } & \text { V2: } & \text { Yes } \\ & \text { V3: } & \text { Yes } & \text { V3: } & \text { Yes } & \text { V3: } & \text { Yes } \\ & \text { V4: } & \text { Yes } & \text { V4: } & \text { Yes } & \text { V4: } & \text { Yes }\end{array}$

NOTE: Small indicates a short causing less than $20 \%$ voltage drop from normal. 


\section{DISTRIBUTION}

1 Casey Barnard - University of Florida

1 Mark Sheplak - University of Florida

$1 \quad$ MS1080 Keith Ortiz

1 MS1080 Paul Galambos

$1 \quad$ MS0899 Technical Library oldmajor@ufl.edu (electronic copy) sheplak@ufl.edu (electronic copy)

1749 (electronic copy)

17492 (electronic copy)

9536 (electronic copy) 


\section{Sandia National Laboratories}

